\title{
Promoting communication, participation, and learning with regard to organic food products: a communication theoretical approach
}

\author{
Peter Kastberg ${ }^{1}$
}

\begin{abstract}
The market for organic foods is growing, however, the proportion of consumers buying organic foods is still considered low. Research shows that a significant barrier to consumers purchasing more organic foods is lack of information. This leads the relevant body of research to call for better communication around organic foods. The same body of research, however, neither questions what good communication surrounding organic foods is, nor what would make it better. Applying the communication theoretical formats of transmission, interaction, and coaction, respectively, onto instances of organic communication activities, I will discuss to what extent each format encourages consumer participation and learning. Transmission, typically in the form of monologuous mass communication, is cost effective. It is also a format that bars a sender, e.g., producer or farmer, from gauging deposits in the consumer, e.g., understanding the message, trusting the sender, etc. Interaction, typically in the form of dialoguous encounters, integrates feedback into communication allowing the sender to appreciate the level of understanding, trust, etc., which the communicative effort has given rise to, albeit at a higher price in terms of money, time, and manpower. In the format of coaction, typically in the form of co-operative endeavors, the deposit is a matter of what is coconstructed by the participants, e.g., understanding, trust, etc. Coaction thus satisfies the organic communicators craving for involving the consumer, and because food is a low-involvement commodity, this is critical. But emancipating the consumer comes at a price. First of all, coactional communication is dependent on highly motivated participants, and second, coactional communication is difficult if not impossible to control. Informed by these insights, I present an in-depth, critical discussion of the promises and pitfalls of how multicriteria assessments may be communicated and coconstructed on a coactional, web-based platform.
\end{abstract}

Key Words: coaction; communication; interaction; knowledge communication; transmission

\section{INTRODUCTION}

Even though the market for organic foods is generally recognized to be growing (Lockie et al. 2002, Dettmann and Dimitri 2012) "the proportion of consumers purchasing organic food on a regular basis remains low" (Aertsens et al. 2009:1104). Among the barriers most commonly found, the consumers' lack of information about the 'attributes' of organic food products is a constant (Zanoli and Naspetti 2002, Duffy et al. 2005, Barnes et al. 2009, Bodini et al. 2009); consequently "consumers' lack of knowledge concerning organic food is an important factor slowing down growth" (Aertsens et al. 2011:1353). Demeritt (2002) even reported that lack of knowledge and awareness was the main reason for consumers not buying organic food. Naturally, there are other barriers. According to Bellows et al. (2008:20), they include but are not limited to "price, store location, food quality or availability, information, trust," etc. These, as well as potential additional barriers, are beyond the scope of this paper. Because of the mundane yet highly consequential fact that in the industrialized part of the world, "producers and consumers no longer know each other" (Bellows et al. 2008:23), strategic communication is inescapable to raise awareness of and to inform about the intrinsic and extrinsic values of food products (Bodini et al. 2009). Zanoli and Naspetti (2002:652) expressed the need "to devise a better communication strategy," with a view to "informing consumers about the extra quality inherent in organic food" (Duffy et al. 2005:374). Although the relevant body of research seems to be united behind a generic call for better organic communication (Conner and Christy 2004), the same body of research seems to take for granted what makes communication good and, somewhat more fundamental but equally unreflected, that we all agree on what communication is. For my purposes, both of these underlying assumptions are seen as highly problematic and will be challenged from both a theoretical and a practical perspective. From a theoretical point of view, the fact that communication is ubiquitous does not make it amorphous, let alone immune to serious systematic investigation. As I will show, the field of communication theory has established a sort of canon of communicative formats, each imbued with discrete strengths and weaknesses. From the point of view of organic communication practices, I will demonstrate that the communicative approach one favors when communicating about organic foods has very practical consequences for what one can see and what one can do in relation to communicating about organic foods.

To situate my work in a disciplinary context relevant to investigating the communication of the "complexities and niceties of organic farming practices and organic food quality attributes" (Yiridoe et al. 2005) and taking into account that lack of information is a key barrier prohibiting potential buyers from purchasing organic foods (Padel and Foster 2005), my work is also informed by public understanding of science (PUS; Knight 2006). Public understanding of science was chosen because it is an acknowledged field of study, which critically investigates the public's exposure to, awareness, and understanding of the advances of science, engineering, and technology as well as their implications for society. Although these two disciplinary fields make up the background of my work, the research project MultiTrust, i.e., multicriteria assessment and communication of effects of organic food systems (http://multitrust.org), which is being conducted under the auspices of the International Centre for Research in Organic Food Systems (ICROFS), is in the foreground. A primary intention of this multifaceted research project is to "make it easier for consumers, citizens and politicians to observe and evaluate the different contributions that organic 
food systems offer", with a special emphasis "to promote communication, participation and learning" about organic foods (MultiTrust 2012). This, in turn, frames my endeavor to add communication theoretical substance, as well as PUS-related insights, to the ongoing discussion of the design and evaluation of communication activities conveying the added value of organic foods to final customers.

Communication theoretical typology guides my approach (this is consistent with, e.g., Beebe et al. 2004, Littlejohn and Foss 2011) and I situate organic 'food quality communications' (Bodini et al. 2009) within a general communication theoretical framework. Even if this typology is generally accepted within the field of communication studies, a caveat should be issued here because in what we may call real-life practical communication activities, these formats do in fact (also) coexist and overlap in various ways. It is, therefore, imperative that they not be perceived as mutually exclusive or incommensurable in the Kuhnian sense (1995, c1962), but rather as incremental or evolutionary expansions (Lakatos 1978 et passim) of one another. I present, critically discuss, and evaluate select, real-life examples or organic communications as instantiations of the communication formats of transmission, interaction, and coaction, respectively. I also point to some of the central theoretical and practical strengths and weaknesses of the different formats of communication in relation to the MultiTrust project in particular and organic communication in general.

\section{COMMUNICATION FORMATS AND DEPOSITS: AN INTRODUCTION}

Instances of organic food communication activities as transmission are monologuous in nature, e.g., a formal lecture held by, say, a spokesperson from USDA Organic in the U.S. or by the EU Ecolabel for Consumers in Europe. Instances of organic food communication activities as interaction would entail some kind of feedback loops, dialogical question-answer sequences at a symposium on organics for instance, whereas instances of organic food communication activities as coaction would be cooperative endeavors, e.g., upstream engagement when it comes to developing and implementing organic policies. Qualitatively, each instantiation spurs a different outcome, a different knowledge deposit, as it were, in the minds of an audience or communication partners. It is crucial to stress that when talking about communicating for the sake of enabling consumers to bridge the information gap (Duffy et al. 2005) and not for aesthetic or other reasons, then, as Dewey pragmatically put it, "the deposit is what counts" (1933). Because an instance of organic food communication as transmission ends with, or actually is, the act of transmitting, we, strictly speaking, have no way of gauging the knowledge deposit of a transmission. In the above case of the lecture, for instance, everything said may have been heard, understood, accepted, and subsequently complied with, but then again it may not. However, when it comes to an interactive instance of organic food communication, the knowledge deposit can, if not measured in any positivistic sense, at least be appreciated on the basis of the interaction itself, e.g., on the number and relevance of questions, of critical remarks put forward by an audience, etc. The deposit emerging from a coactional instance of organic food communication, on the other hand, is gaugeable on the basis of the cooperative activity itself, i.e., the deposit is what the participants in the communication activity themselves negotiate, what they are able to coconstruct.
I will elaborate on these formats of communication by means of illustrative empirical examples. I will demonstrate that the communication format chosen critically influences the impact of any instance of organic communication, and, in the process, raises questions as to the nature and consequences of these influences.

The examples presented are prototypical expressions (Kleiber 1993) of different kinds of organic communication activities. At the core of each format's prototypicality stand its mediational potential and the degree to which each format may be said to afford deposits in the sense of Dewey (1933).

\section{Organic food communication as transmission}

Communicating about organic food products to final consumers in the format of transmission is carried out as a linear process from a sender to a receiver (Theodorson and Theodorson 1969), typically as a traditional mass communication activity aimed at informing a public. This mirrors what has been labeled $1^{\text {st }}$ generation PUS research and the idea of the 'deficit model' (Miller 2001). If we translate this idea to organic communication as transmission, the point of departure is that (1) the public is in a knowledge deficit when it comes to basic knowledge of organics, and that (2) this state of affairs needs to be rectified. Consequently, emphasis is on instilling in the public a sort of organic literacy. In a study by Duffy et al. (2005:23), it was shown that "the majority of [organic] organisations" do in fact rely on mass media "to communicate their campaign messages as it provides the opportunity to reach millions of people at minimal cost." Communication wise the ideology of transmission is oriented toward the sender, i.e., communication is primarily a matter of sending out messages while trying to avoid 'noise' (Shanon and Weaver 1949). Strictly speaking, it is not of primary interest what the receiver may retain from the communication activity, because within the horizon of this ideology, it goes without saying that the receivers retain what is transmitted. From the point of view of more recent communication theory it is, however, well known that even if all viewers or listeners are offered the same kind of information, in the same way, this does not imply that they retain the same information, or if they retain at all.

It is evident that the idea behind much organic informational labeling is tarnished by the brush of transmission, in the sense that putting a label on a product apparently equals communicating about said product. The problem is that any labeling is rendered futile if the consumer does not understand it. Consequently it was no surprise, when Janssen and Hamm (2010) told us that when the mandatory new European Union logo for organic food targeted at final customers was introduced on an EU-wide scale, it did not in and of itself ensure that the logo was understood, let alone trusted by the consumers. As Connor and Christy (2004:42) pointed out "consumer misunderstanding of the [organic] label's meaning points to a need for better communication if the label is to function optimally." In communication theoretical terms, we may conclude that although transmission may be necessary, it is not sufficient. If it were sufficient, it would imply that we sanction the idea of the receiver as 'the empty vessel' (Feiman-Nemser and Remillard 1995) or of the 'recitation model' (Eisner 1991) of communication and, in more general $1^{\text {st }}$ generation PUS terms, acknowledge an underlying 'deficit model.' There is, however, no algorithm for human understanding based on a simple input-output logic, and, 
more specifically, no evidence to support a causal relationship between communicated output and retention in receivers. That is also why the idea of gauging the effectiveness of organic (mass) communication "based on the amount of media coverage generated" (Duffy et al. 2005:24) will not render applicable insights, as it "provides no feedback on the acceptance/ understanding of the message(s) communicated or any impacts, direct or indirect, on purchasing/consumption behaviour, attitudes and perceptions." To gauge an effect, be it in the form of understanding, of increased sales, or the like, "it is important to make the ex post effort to evaluate what impact this informational labeling is having" (Caswell and Mojduszka 1996:1248) so that it not "remain the subject of conjecture" (Duffy et al. 2005:24). In communication terms, this translates into the need for supplementary or follow-up activities of an interactive nature.

\section{Organic food communication as interaction}

Communicating about organic foods in the form of interaction is typically carried out as demonstrations, fairs, or shows. Such demonstrations, fairs, or shows tend to center on either explaining, and in the process, marketing, select benefits of organic food products, or of reenacting a particular 'from farm to fork' process, or parts of it, in front of an audience. Like in a transmission approach, communication of the interactive format is also typically initiated and performed by experts, i.e., producers or farmers. In stark contrast to the first format of communication, however, for this format of communication to thrive there must be interaction between the actors involved, e.g., experts interacting with lay audiences or sellers interacting with customers. Being interactive, this format of communication does not, in fact cannot, take place merely because a sender has sent, so to speak, but occurs once a receiver has, in one way or the other, interacted with a sender (Katz and Kahn 1978). The interaction typically takes place on two levels: (1) between actor and audience, and (2) between audience, actor, and the props used in the interactional communicative setting in question. Although this format is closely related to dialoguous learning formats (Perkins 2009), it is often qualified significantly by the fact that verbal communication is integrated into the practice of going through a process, a process which may also incorporate tactile and/or kinesthetic elements. It could be hands-on participation in conducting an experiment, e.g., for a school class to churn its own butter at an organic farm in lieu of a 'visit an organic farm' program like the one sponsored by the UK Soil Association. Or it could be taking a 'farm to table class for adults' course at, say, The Garden of Eve's, New York, in which course participants both harvest, produce, and prepare their own organic meals. As a contrast to the transmission format, the deposit in the audience resulting from interactive communication can be appreciated in different ways. In both of the above examples, the end products, butter and a meal, respectively, are literally both tangible and edible, and, as such, offer themselves up for subsequent appreciation and evaluation. When it comes to the more intangible deposit, so to speak, the proximity, or even intimacy, of cooking a meal together or of standing around a table where a demonstration takes place, allows an audience to give instantaneous feedback in the form of questions and comments, and of handling the props and instruments involved in the process. Not only is the audience encouraged to interact, but it is critical to both process and product that they do so.
Another less kinesthetically oriented instantiation of an interactive organic communication format is the 'citizen jury' experiment conducted by Barnes et al. (2009). Over a period of a few days, select citizens were introduced to an in-depth body of knowledge about, among other things, organic dairy farming. In the process, the citizen jury was encouraged to deliberate issues pertaining to this subject among themselves and with the expert instructors. In terms of deposit, a pre- and post-exposure audit was carried out. As an appreciable deposit, the citizen jury experiment "helped to improve [citizens'] knowledge of the topics of dairy farming and the differences between organic and conventional production" (Barnes et al. 2009:159). Among other things, this increase in organic knowledge resulted in the stated preference that "[m]ean willingness to pay" more for organic milk compared to conventional milk had increased after the citizen jury (Barnes et al. 2009). This may, at first glance, seem to constitute the "lemonade springs and peppermint trees" (Teague 1993) of organic communications, the relevant body of organic research is less enthusiastic. Although most consumers harbor positive attitudes toward organic foods (Aertsens et al. 2011), it does not suffice to rely on positive attitudes to sell organic foods. For as Bellows et al. (2008:i) have demonstrated, a positive attitude toward organic foods does not "translate into [the] corresponding ... organic food consumption behavior." In essence, there is "a sharp discrepancy between organics purchasing behavior and the importance that consumers place on organic production methods when deciding what to eat" (Bellows et al. 2008:1). Public understanding of science research corroborates this; in what is known as $2^{\text {nd }}$ generation PUS research, scholars would initially also embrace the idea that 'the more you know, the more you love it'. But later PUS research demonstrated that although there is certainly a correlation between knowledge of and trust in, say, a technical product, it is not necessarily a causal one, i.e., along the lines of 'knowledge breeds understanding' (Bauer et al. 2007). So although interactive endeavors seem to harbor promises for the organic foods industry, Barnes et al. (2009:162) ended with the sobering statement that for reasons of time and money, "[c]learly it is not feasible to provide the detailed information that was offered within the [citizen jury] to the general consumer."

Being interactive, the above examples tend to be a mixture of play and performance in a wider sense of the word (Schechner 2002) and are thus closely related to learning how to play a game while actually playing it and at the same time being mentored by a more knowledgeable person. Here I focus on the field of business to consumer communication, but in the business to business section of the organic market, there are also instantiations of interactive communications, e.g., the Nordic Organic Food Fair in Sweden, the Natural Food Show in the UK, and the Biofach Exhibition in Germany, to mention but a few of the bigger events. If we take a closer look at Biofach, interactivity is systematized here because it features the Biofach Congress, a forum in which organic stakeholders, i.e., business and industry, NGOs, and politicians, are encouraged to deliberate and debate preselected issues concerning the organic sector. Even if this format of communication does spur an interactional relationship, it does not however spur a reciprocal one. Returning to organic products, the point of departure for interactive communication still positions the expert, e.g., the farmer, the chef, or the like, as 'sender' and the average consumer, typically a nonexpert when it comes to organic products and processes, as the 'receiver.' This, 
in turn, means that the point of reference, the endpoint of interactive communication, is the expert's knowledge; and not so much what the receiver may bring to qualify this knowledge. In other words, the absolutism of expertise and the absolutism of the position that holds it are not questioned, and in that respect, interaction resembles transmission. In communication theoretical vocabulary: even if participants are invited to react, they are neither encouraged nor expected to coact. And it is primarily in this respect that interaction differs radically from coaction.

\section{Organic food communication as coaction}

The organic communication activities, which I label coactional, are in two important respects quite different from the previous two formats of communication. First of all, being coactional means that the traditional roles of sender and receiver are no longer adequate. As a coctional endeavor, a communication activity is coconstructed by its participants (Tomasello 2008). Second, what is thus cocreated (Barnlund 1980, Rogers and Kincaid 1981), be it a product, a service, or the ability to conduct multicriteria assessments regarding organics, although it typically is the pinnacle of the work carried out by the participants, is not the core activity per se. The core activity is the coactional communication process itself. Much as the roles of actor and audience, of sender and receiver, become interchangeable under the common denominator 'participants,' process and product also become less easily definable entities.

To illustrate a coactional communication activity, I allow myself to digress slightly from the realm of organics to present and discuss the Danish "MathTheater," a coactional endeavor par excellence. Spurred by the experience that many fifth graders would agree with Knight's (2006:2) laconic statement "that much science is rather dull," a group of teachers paired up with a drama and a math consultant to see if the theater format might change that perception, at least for one group of fifth graders. Under the guidance of experts, i.e., teachers and consultants, the children would design, develop, and produce their own MathTheater play and in the process transform a standard fifth grade math syllabus into a theater performance; a performance that the children eventually performed before an audience of other children, teachers, and parents. In terms of scenography and plot, the play featured, among other things, a cardboard castle lived in by medieval knights wearing geometrically shaped shields and armor. The greedy knights would hoard gold, meticulously weigh the heavy metal, and argue among themselves over who would be allotted what percentage of the gold. In another act pirates would roam the Caribbean, measure the nautical miles travelled, and, on their journey, discover an uninhabited, exotic island. Here they would ponder the geometrical shape of the island's volcano, a truncated cone, as it turned out, all the while drinking rum and fighting among themselves as true pirates do. In the final act, on a perilous scientific expedition to Greenland, the weight of ice as well as the crystalline structure of snowflakes would be duly measured and documented.

When it comes to the deposit, neither the play nor the process was an add-on to math class; they were in fact math class. The children were not merely the audience of transmitted scientific knowledge neither were they merely to interact with predefined demonstrations; the children were in fact coacting with their teachers as well as with each other and, thus, coconstructing both the process as well as the end result. Concretely, in the process of making the dialogue, which they were later to perform, comprehensible to themselves, they were in effect making math comprehensible to themselves. In terms of deposit, the play itself became a testimony to what the children had learned. Despite these indisputable, coactional qualities, this communication format seldom occurs. Apart from the fact that it takes a certain willingness on behalf of all participants, in this case children and teachers, as well as a certain training, in this case especially on behalf of the teachers, coactional activities are often also dependent on the possibility to alter the mindset of whoever is funding the activity, in this case the school's management.

Returning once more to communicating about organic foods, it is safe to say that the coactional format of communication, in which the status of product and process as well as that of sender and receiver become negotiable, is by far be the most radical one. However, although it may seem both elaborate and time consuming, the underlying idea corresponds quite nicely to an idea of co-operation, not unfamiliar to many farming cultures. In many ways, the underlying idea is congenial to thoughts fostered by the agricultural cooperative movement, especially in Northern Europe but also elsewhere. Needless to say, the urban revival of core aspects of these thoughts are expressed in the modern-day, organic food co-ops found in many inner cities, as well as in community or corporate gardening projects. Despite the fact that it is not an all-organic endeavor, the member-owned U.S. agricultural cooperative, Land O'Lakes, Inc.'s Answer Plot Community Garden initiative may serve as a large scale example not only of distributed community gardening but also of coaction. As such it corresponds quite well with what Conner and Christy (2008) called for when requesting that "activist, consumer groups and producer groups should cooperate" to engage "people in initiatives to help themselves" (Jackson 2005). In the case of the Answer Plot Community Garden initiative, the aim is to help alleviate hunger in rural U.S. communities. Returning to Bellows et al. (2008:23) it is conceivable that the organic "farmers and environmentalist might well benefit from developing alliances with those who value organic production methods" in a similar way.

Put in coactional terms, the process of establishing and of maintaining an organic community garden may, to the participants, very well be as rewarding and valuable as harvesting, distributing, and/or consuming the produce. Conflating process and product, communicatively speaking, is a quality that merits that this format of communication be perceived as an instantiation of $3^{\text {rd }}$ generation PUS activities. A move toward participatory science governance (Bora and Hausendorf 2006), democratizing (McCormick 2007), and participation and convergence (Kastberg 2007, 2010) is clearly visible. And although this move intrinsically aims at spurring engagement and involvement in a low 'involvement good' (Bodini et al. 2009), it is also both costly and quite demanding in terms of energy and time compared to the other two formats introduced.

\section{CONSIDERING MULTITRUST}

Let me discuss some of the central strengths and weaknesses of the different formats of communication in relation to organic communication and the MultiTrust project (Alroe and Noe $2014 a$ ). It has become quite clear that the issue of promoting 
communication, participation, and learning about organic foods is even less straightforward than seemed initially. If we take seriously that the public not only needs to be exposed to a new EU logo, but that communication means "to make clear what the new logo stands for and remove unfounded consumer concerns" (Janssen and Hamm 2010:335), then we also need to take seriously that gauging the deposit of whatever communicative endeavor we perform is critical to our success. Consequently, if an ensuing postcommunicative performance, e.g., decision making by the final customer, is a criterion for gauging our communicative success, then transmission cannot stand alone. Although all sorts of content may be easily transmittable at the click of a mouse, reception, understanding, and any ensuing operationalizing based on this understanding is not. From the point of view of communication theory, we need to turn to interaction and/or coaction. However, interactional and coactional communicative endeavors hold other problems. For these two appreciations of communication, it is not enough to transmit; a prerequisite for communication to take place is engaging an audience, albeit in different ways. When we speak of communication as interaction, we also speak of feedback loops. The prototypical feedback loop is the question-answer sequence of dialogue. And although faceto-face dialogue is a fine way to try to ensure understanding and compliance, or in more neutral terms, operation, it is also quite costly. Appreciating the fact that supervising and/or tutoring each MultiTrust stakeholder, or any would-be organic consumer, is not a viable option, but that does not imply that we must abandon interaction altogether. Neither does embarking on a coactional communicative endeavor necessarily imply that one must enter the world of drama. The so-called new medias offer ample possibilities for both interactional and coactional communication. Consequently, the MultiTrust project has envisioned an Internetbased platform aimed at promoting communication, participation, and learning about organic foods (Alroe and Noe $2014 b$ ). The gist of the platform is presented in the Danishlanguage, color animation film MultiTrust Animation Film (http:// www.youtube.com/watch?v=zmoXYJAS8LY; for an in-depth, communication-theoretical analysis of this animation see Kastberg 2014). This platform will be presented and discussed from a communication theoretical perspective.

The platform envisioned rests on two general assumptions: first, that each stakeholder (Freeman 1984) in the 'from farm to fork' value chain, i.e., in crude generalization, the farmer, processor, seller, or consumer, harbors different criteria for determining what good organic food is. What the consumer of organic meat sees as good organic practice may be too expensive for the farmer to adhere to, too time consuming in the processing plant, too logistically demanding for the seller, etc. Acknowledging the differences for the decision-making basis of each stakeholder translates to the first dimension of multicriteria assessment. The second general assumption reads that each stakeholder makes decisions, be it with regards to fodder, store display, purchase, etc., based on not one, but multiple criteria. For the consumer of organic meat, for instance, one criterion may be that the animal has been feeding on organic fodder, another that the animal has been treated better than stipulated by current law, a third that the transportation of the animal from farm to processing plant has been humane, etc.

Acknowledging that the consumer is basing his/her decision on multicriterial assessments, and that the same holds true for each stakeholder involved, as well as the fact that these multiple criteria may be at odds with one another, translates to the second dimension of multicriteria assessment. Recognizing these two dimensions, as well as the second order nature of their interconnectedness, leaves us with a hyper complex (Qvortrup 2003) understanding of the communicative setting. It is exactly this nuanced understanding that calls for the coactional communication format to be the dominant one. Although my research has a communication-theoretical point of view, other project researchers investigate from other perspectives, for a list of project partners, ranging from food economy over agroecology to learning and media studies, please visit the project website at http://multitrust.org. Needless to say, the platform features transmission, i.e., all stakeholders can post blogs, upload documentation, etc., and it features interaction, i.e., all stakeholders can comment on the postings or documentation of all other stakeholders. But the raison d'être of the platform is its capacity to constitute the agora-like (Nowotny et al. 2001) virtual environment called for, allowing all stakeholders to cooperate in coconstructing content, in this case multicriteria assessments. The end-goal of the platform, then, is not one of transmitting one's own assessment or of merely reacting to the assessments of others, it is one of negotiating assessments among stakeholders. That is, communication on the platform does not stop once a farmer has uploaded an assessment of a particular organic practice on his or her farm, nor once a consumer has reacted to this assessment by rating it in a blog. Communication stops, if at all, once all stakeholders in principle have taken part in negotiating the assessment in question. Consequently, and in tune with the coactional format, any communication, and therefore any assessment thus coconstructed, on the platform are in principle open-ended, allowing for ever more nuanced assessments.

\section{DISCUSSION AND CONCLUSIONS}

The platform envisioned addresses the core "questions on how to increase involvement and reduce uncertainty in relation to organic food consumption" (Aertsen et al. 2009:1158). In relation to the question of involvement, there is little doubt that communication of the coactional variety mirrors the Zeitgeist of late or postmodern societies inclined to favor deliberative and participatory public engagement (Putnam 2004) and aimed at empowerment and emancipation. Coactional communication, of the sort envisioned on the platform, is however also quite demanding. Even if coactional activities constitute the current capstone of communication theory, as well as being advocated by current $3^{\text {rd }}$ generation PUS research, there is no guarantee that (all) stakeholders are willing or able to participate. From the point of view of the consumer, for instance, a sprouting denialism (Diethelm and MacKee 2009), a growing decision fatigue among citizens of industrialized societies, and, generally speaking, information overload, as well as the consumer's "relative transaction costs for becoming informed" (Caswell and Mojduszka 1996:1248) should be considered. A coactional platform might, however, be able to piggyback on the increasing popularity of sharing content as well as conducting ratings on social media. Naturally, the coactional nature implies that content creation, e.g., assessing and rating, is left to 'Groundswell' ( $\mathrm{Li}$ and Bernoff 2011) or to Wikipedia-style mechanisms. Needless to say, this imposes severe restrictions on control over content, a fact that commercial stakeholders may not welcome let alone accept. In relation to the question of reducing uncertainty, Padel and Forster 
(2005), among others, have shown that consumers question the validation of both the organic product as well as organizations validating the organic product. Lockie et al. (2002:29) stressed the importance of "independent certification of organic status." Qua coactional, the platform could, in addition to constituting a communicative "uncertainty reduction" device (Berger and Bradac 1982), become, or at any rate, pave the way for a novel kind of stakeholder-driven, cooperative third party validation institution altogether. And this, then, is also exactly where we may establish a potentially fruitful theoretical meeting place between communication theory and the general quest for the reduction of complexity (Luhmann 1995, c1984 et passim) of late or postmodern societies (Lyotard 1984, c1974).

As we have seen, communication seen and performed as coaction holds promising qualities with regard to promoting communication, participation, and learning about organic foods to relevant stakeholders. It offers a participative and deliberate way to enable multicriteria assessments of the "complexities and niceties of organic farming practices and organic food quality attributes" (Yiridoe et al. 2005), more so than communication seen and performed as transmission or interaction. Needless to say, to corroborate or nuance the above insights, large-scale empirical studies of organic communication formats and their effects on relevant stakeholders is called for. Especially interesting in this context would be studies aimed at analyzing stakeholders' willingness to partake in a coactional endeavor, as well as stakeholders' expectations toward possible deposits, in the Deweyan sense.

\section{Responses to this article can be read online at:} http://www.ecologyandsociety.org/issues/responses. $\mathrm{php} / 7139$

\section{LITERATURE CITED}

Aertsens, J., K. Mondelaers, W. Verbeke, J. Buysse, and G. van Huylenbroeck. 2011. The influence of subjective and objective knowledge on attitude, motivations and consumption of organic food. British Food Journal 113(11):1353-1378. http://dx.doi. org/10.1108/00070701111179988

Aertsens, J., W. Verbeke, K. Mondelaers, and G. van Huylenbroeck. 2009. Personal determinants of organic food consumption : a review. British Food Journal 111(10):1140-1167. http://dx.doi.org/10.1108/00070700910992961

Alrøe, H. F., and E. Noe. 2014a. How can we know if organics becomes better? A perspectivist view on multicriteria assessment. Pages 191-194 in G. Rahmann and U. Aksoy, editors. Proceedings of the 4th ISOFAR scientific conference: building organic bridges. International Society of Organic Agriculture Research, Trenthorst, Germany. [online] URL: http://hugo.alroe.dk/files/ Work/2014-Alroe_Noe-How can_we know if_organics_becomes better. pdf

Alrøe, H. F., and E. Noe. 2014b. A prototype tool for participatory multicriteria assessment to develop organic food chains. Pages 195-198 in G. Rahmann and U. Aksoy, editors. Proceedings of the 4th ISOFAR scientific conference: building organic bridges.
International Society of Organic Agriculture Research, Trenthorst, Germany. [online] URL: http://hugo.alroe.dk/files/ Work/2014-Alroe Noe-A prototype tool for participatory multicriteria_assessment to develop_organic_food_chains.pdf

Barnes, A. P., P. Vergunst, and K. Topp. 2009. Assessing the consumer perception of the term "organic" : a citizens' jury approach. British Food Journal 111(2):155-164. http://dx.doi. org/10.1108/00070700910931977

Barnlund, D. C. 2008. A transactional model of communication. Pages 47-57 in C. D. Mortensen, editor. Communication theory. 2nd edition, Transaction, New Brunswick, New Jersey, USA.

Bauer, M. W., N. Allum, and S. Miller. 2007. What can we learn from 25 years of PUS survey research? Liberating and expanding the agenda. Public Understanding of Science. 16:79-95. http://dx. doi.org/10.1177/0963662506071287

Beebe, S. A., S. J. Beebe, and D. K. Ivy. 2004. Communication: principles for a lifetime. 2nd edition. Pearson, Boston, Massachusetts, USA.

Bellows, A. C., B. Onyango, A. Diamond, and W. K. Hallman. 2008. Understanding consumer interest in organics: production values vs. purchasing behavior. Journal of Agricultural and Food Industrial Organization 6:1. http://dx.doi.org/10.2202/1542-0485.1169

Berger, C. R., and J. J. Bradac. 1982. Language and social knowledge: uncertainty in interpersonal relations. Edward Arnold, London, UK.

Bodini, A., T. Richter, and R. Felder. 2009. Quality related communication approaches for organic good. Journal of Food Products Marketing 15:364-377. http://dx.doi.org/10.1080/1045$\underline{4440902942117}$

Bora, A., and H. Hausendorf. 2006. Participatory science governance revisited: normative expectations versus empirical evidence. Science and Public Policy 33(7):478-488.

Caswell, J. A, and E. M. Mojduszka. 1996. Using informational labeling to influence the market for quality in food labeling. American Journal of Agricultural Economics 78:1248-1253. http:// dx.doi.org/10.2307/1243501

Conner, D., and R. Christy. 2004. The organic label: how to reconcile its meaning with consumer preferences. Journal of Food Distribution Research 35(1):40-43. [online] URL: http:// ageconsearch.umn.edu/bitstream/27135/1/35010040.pdf

Dettmann, R. L., and C. Dimitri. 2012. Who's buying organic vegetables? Demographic characteristics of U.S. consumers. Journal of Food Products Marketing 16:79-91. http://dx.doi. org/10.1080/10454440903415709

Diethelm, P., and M. MacKee. 2009. Denialism: what is it and how should scientists respond? European Journal of Public Health 19(1):2-4. http://dx.doi.org/10.1093/eurpub/ckn139

Demeritt, L. 2002. All things organic 2002. A look at the organic consumer. Audio file. Hartman Group, Bellevue, Washington, USA.

Dewey, J. 1933. How we think: a restatement of the relation of reflective thinking to the educative process. D.C. Heath and Company, Boston, Massachusetts, USA. 
Duffy, R., A. Ferne, and V. Healing. 2005. Reconnection in the UK food chain : bridging the communication gap between food producers and consumers. British Food Journal 107(1):17-33. http://dx.doi.org/10.1108/00070700510573177

Eisner, E. W. 1991. The enlightened eye: qualitative inquiry and the enhancement of educational practice. Macmillan, New York, New York, USA.

Feiman-Nemser, S., and J. Remillard. 1995. Perspectives on learning to teach. Issue Paper 95(3):1-35. Michigan State University, East Lansing, Michigan, USA. [online] URL: http:// ncrtl.msu.edu/http/ipapers/html/pdf/ip953.pdf

Freeman, R. E. 1984. Strategic management: a stakeholder approach. Pitman, Boston, Massachusetts, USA.

Jackson, T. 2005. Motivating sustainable consumption - a review of evidence on consumer behaviour and behavioural change. A report to the Sustainable Development Research Network. Centre for Environmental Strategy. University of Surrey, Surrey, UK. [online] URL: http://www.worldresourcesforum.org/files/file/ Jackson $\% 20-\% 20$ Motivating $\% 20$ Sustainable $\% 20$ Consumption $\%$ 20(abstract-chapter11-chapter12).pdf

Janssen, M., and U. Hamm. 2010. The mandatory EU logo for organic food: consumer perceptions. British Food Journal 114 (3):335-352. http://dx.doi.org/10.1108/00070701211213456

Kastberg, P. 2007. Knowledge communication - the emergence of a third order discipline. Pages 7-24 in C. Villiger and $\mathrm{H}$. Gerzymisch-Arborgast, editors. Kommunikation in bewegung multimedialer und multilingualer wissenstransfer in der expertenlaien kommunikation. Verlag Peter Lang, Frankfurt, Germany.

Kastberg, P. 2010. Knowledge communication - formative ideas and research impetus. Programmatic Perspectives 2(1):59-71. [online] URL: http://pure.au.dk/portal/en/publications/knowledgecommunication--formative-ideas-and-research-impetus $\% 285$ eecb 390 e0a5-11de-afb9-000ea68e967b\%29.html

Kastberg, P. 2014. Animating domain-specific complex knowledge: an analysis of organic food communication. Journal of Translation and Technical Communication Research, in press.

Katz, D., and R. L. Kahn. 1978. The social psychology of organizations. 2nd edition. Wiley and Sons, New York, New York, USA.

Kleiber, G. 1993. Prototypensemantik: eine einführung. Francke Verlag, Tübingen, Germany.

Knight, D. 2006. Public understanding of science: a history of communicating scientific ideas. Routledge, New York, New York, USA.

Kuhn, T. S. 1995, c1962. The structure of scientific revolutions. Chicago University Press, Chicago, Illinois, USA.

Lakatos, I. 1978. The methodology of scientific research programmes. Philosophical Papers Volume 1. Edited by John Worral and Gregory Currie. Cambridge University Press, Cambridge. UK. http://dx.doi.org/10.1017/CBO9780511621123

Li, C., and J. Bernoff. 2011. Groundswell, expanded and revised edition: winning in a world transformed by social technologies. Harvard Business Review Press, Boston, Massachusetts, USA.
Littlejohn, S. W., and K. A. Foss. 2011. Theories of human communication. 10th Edition. Waveland, Long Grove, Illinois, USA.

Lockie, S., K. Lyons, G. Lawrence, and K. Mummery. 2002. Eating 'green' : motivations behind organic food consumption in Australia. Sociology Ruralis, 42(1):23-40. http://dx.doi. org/10.1111/1467-9523.00200

Luhmann, N. 1995, c1985. Social systems. Translated by John Bednarz, Jr. with Dirk Baecker. Stanford University Press, Stanford, California, USA.

Lyotard, J.-F. 1984, c1979. The postmodern condition: a report on knowledge. Manchester University Press, Manchester, UK.

McCormick, S. 2007. Democratizing science movements: a new framework for mobilization and contestation. Social Studies of Science 37(4):609-623. http://dx.doi.org/10.1177/0306312707076598

Miller, S. 2001. Public understanding at the crossroads. Public Understanding of Science 10:115-120. http://dx.doi. org/10.1088/0963-6625/10/1/308

MultiTrust. 2012. Multicriteria assessment and communication of effects of organic food systems: project summary. International Centre for Research in Organic Food Systems, Tjele, Denmark. [online] URL: http://multitrust.org

Nowotny, H., P. Scott, and M. T. Gibbons. 2001. Re-thinking science: knowledge and the public in an age of uncertainty. Blackwell, Cambridge, UK.

Padel, S., and C. Foster. 2005. Exploring the gap between attitudes and behaviour: understanding why consumers buy or do not buy organic food. British Food Journal 107(8):606-625. http://dx.doi. org/10.1108/00070700510611002

Perkins, D. 2009. Making learning whole: how seven principles of teaching can transform education. Jossey Bass, San Francisco, California, USA.

Putnam, H. 2004. Ethics without ontology. Harvard University Press, Boston, Massachusetts, USA.

Qvortrup, L. 2003. The hypercomplex society. Peter Lang, Frankfurt, Germany.

Rogers, E. M., and D. L. Kincaid. 1981. Communication networks: toward a paradigm for research. Free Press, New York, New York, USA.

Schechner, R. 2002. Performance studies: an introduction. Routledge, London, UK.

Shannon, C. E., and W. Weaver. 1949. The mathematical theory of communication. University of Illinois Press, Urbana, Illinois, USA.

Teague, B. 1993. "Retooling" as an adaptive skill for translators. Scientific and Technical Translation. VI:161-172. http://dx.doi. org/10.1075/ata.vi.13tea

Theodorson, S. A., and G. R. Theodorson. 1969. A modern dictionary of sociology. Crowell, New York, New York, USA.

Tomasello, M. 2008. Origins of human communication. MIT Press, Cambridge, Massachusetts, USA. 
Yiridoe, E. K., S. Bonti-Ankomah, and R. C. Martin. 2005. Comparison of consumer perceptions and preference toward organic versus conventionally produced foods: a review and update of the literature. Renewable Agriculture and Food Systems 20(4):193-205. http://dx.doi.org/10.1079/RAF2005113

Zanoli, R., and S. Naspetti. 2002. Consumer motivations in the purchase of organic food: a means-end approach. British Food Journal 104(8):643-653. http://dx.doi.org/10.1108/00070700210425930 